\title{
Multiple clinical and biological autoimmune manifestations in 50 workers after occupational exposure to silica
}

Julio Sanchez-Roman, Ingeborg Wichmann, Javier Salaberri, Jose M Varela, Antonio Nuñez-Roldan

\begin{abstract}
Objectives-A self referred group of four workers from a factory producing scouring powder with a high silica content showed a surprisingly high number of features compatible with a connective tissue disease. Further subjects working at the same factory were subsequently studied to evaluate the relation between this exposure and the development of autoimmune processes.

Methods-A total of 50 subjects (44 women, six men; mean (SD) age $43 \cdot 7$ (5.5) years; mean duration of employment 6.1 years) underwent a prospective study including clinical history and physical examination, an immunobiological study, HLA typing, radiological and functional oesophageal and respiratory examination, ophthalmological examination, and isotopic testing of salivary glands.
\end{abstract}

Results-Symptoms of a systemic illness were present in $32(64 \%)$ subjects: six with Sjögren's syndrome; five with the criteria for systemic sclerosis; three with systemic lupus erythematosus (SLE); five with an 'overlap syndrome'; and 13 with undifferentiated findings not meeting the criteria for a defined disease. Antinuclear antibodies were present in $36(72 \%)$ subjects; four had antibodies to native DNA, including two subjects with SLE, one with systemic sclerosis associated with secondary Sjögren's syndrome, and one with overlap syndrome. Anticentromere antibodies were not detected. The frequency of HLA-DR3 was increased in the clinically affected subjects, but did not reach statistical significance.

Conclusions-This descriptive study emphasises the high probability of workers occupationally exposed to silica developing a multiple spectrum of clinical and serological autoimmune manifestations.

(Ann Rheum Dis 1993; 52: 534-538)

In 1914 Bramwell $^{1}$ showed an increase in the occurrence of scleroderma in stone masons and in 1953 Caplan $^{2}$ reported a relation between a pulmonary disease in patients with silicosis and rheumatoid arthritis, although he did not establish a relation between silica exposure and the development of polyarthritis.
Erasmus, ${ }^{3}$ in 1957, and Rodnan et al, ${ }^{4}$ in 1966 , showed an association between silicosis and the development of a specific systemic disease, scleroderma. Since then, isolated studies reporting various alterations in the immune response in subjects exposed to silica have been reported. This paper describes the clinical and biological manifestations observed in 50 subjects occupationally exposed to silica and analyses the surprising heterogeneity of these manifestations.

\section{Subjects and methods}

STUDY POPULATION

The study group consisted of an opportunistic sample of 50 workers (six men and 44 women) who had been working for a mean of $6 \cdot 1$ years at a scouring powder factory located in the outskirts of Seville, Spain. The workers ground and handled the silica that was the main component (about $90 \%$ ) of a scouring powder. The first four subjects were self referred because of clinical symptoms. When it was realised that these subjects had a high number of collagen disease related symptoms in common, they were encouraged to contact their excolleagues and siblings exposed to the same agent, even if they had no subjective disease, to evaluate their clinical status. In this sense, some of the later subjects were 'recruited'. The only selection criterion was to have been working at the factory and handling the powder. Most of the data about the working environment came from the subjects themselves; the factory had been closed for about 10 years before the first subjects were studied.

STUDY PLAN

The subjects were evaluated by a protocol established by the unit for collagen diseases.

Clinical history and physical examination data were obtained by members of the unit for collagen diseases. The American Rheumatism Association (ARA) criteria for the diagnosis of the connective tissue diseases were applied. For systemic lupus erythematosus (SLE) the ARA criteria applied were those of Tan et $a l^{5}$ and for systemic sclerosis the criteria of the Subcommittee for Scleroderma Criteria of the ARA were used. ${ }^{6}$ Patients with 'overlap syndrome' express evident features of SLE and systemic sclerosis. 'Undefined collagen disease' was classified as described by De Portugal et al ${ }^{7}$ 
and Le Roy et al. ${ }^{8}$ Sjögren's syndrome was diagnosed by the existence of (a) keratoconjunctivitis sicca lachrymal hyposecretion (Schirmer's test) coexistent with 'puncatate or filamentary keratitis' (positivity to rose bengal and slit lamp) or (b) abnormalities in the salivary glands explored by gammagraphy with technetium-99 labelled sodium pertechnetate. ${ }^{9}$

For the immunobiological studies, the levels of serum immunoglobulins C3 and C4 (lower limit of normal values 800 and $200 \mathrm{mg} / \mathrm{l}$ respectively) were measured by nephelometry. Rheumatoid factor was measured by latex agglutination. The presence of cryoglobulins was evaluated by serum precipitation of $1^{\circ} \mathrm{C}$. Antinuclear antibodies were measured by indirect immunofluorescence on unfixed rat tissue (liver, kidney, and stomach). Native DNA was determined on a Crithidia luciliae substrate and anticentromere antibodies and antinuclear antibodies on HEp-2 cells. Results were considered positive if fluorescence was present at a titre of $1 / 40$ or higher for the rat and HEp-2 substrates and 1/10 for Crithidia luciliae. Autoantibodies against extractable nuclear antigens were measured by immunodiffusion and counterimmunoelectrophoresis using rabbit thymus and human spleen extracts as the source of antigens.

HLA class I and II antigens were typed using the standard National Institutes of Health microlymphocytotoxicity assay with the International Histocompatibility Workshop reagents and locally available serum samples.

Radiological studies (UICC classification) ${ }^{10}$ and functional studies of the lungs included conventional spirometry and measurement of total lung capacity, maximum inspiratory pressure, and arterial blood gases.

Oesophageal studies included morphological (barium roentgenogram) and functional studies using a method modified from Tolin and Fisher ${ }^{11}$ : administration of $5.55 \mathrm{kBq}$ colloidal technetium-99m diluted in $15 \mathrm{ml}$ water in decubitus in one swallow. Computer images were obtained at a rate of one frame a second for 60 seconds and one frame a 15 second for 10 minutes.

Ophthalmological studies included Schirmer's test and biomicroscopy after staining with rose bengal.

Isotopic testing of the salivary gland function was performed by gammagraphy after intravenous administration of $185-370 \mathrm{kBq}$ technetium- $99 \mathrm{~m}$ labelled pertechnetate.

\section{STATISTICAL ANALYSIS}

Data were analysed by Student's $t$ test (continuous variables) and the $\chi^{2}$ test with Yates's correction and Fisher's exact test (categorical variables). A difference was considered statistically significant if $p \leqslant 0 \cdot 05$.

\section{Results}

EPIDEMIOLOGICAL DATA

The subjects were studied 10 years after working with silica. We calculated that about
300 subjects had been exposed during the 10 years of factory operation (this figure was obtained by data provided by the workers themselves and from legal documents related to claims for compensation). The 50 subjects studied represent $17 \%$ of the total number of workers. There were six men and 44 women; the workers reported that there was an overall predominance of women in the factory. Their mean (SD) age was $43.7(5 \cdot 5)$ years ranging from 34 to 60 years. In this study group, five pairs of siblings and two groups of three siblings were found (brothers and sisters).

The workers were all exposed to the same agent in one single room, with no other known hazardous exposures in the workplace. The intensity of the individual exposure was difficult to evaluate due to a lack of available data. Only the exposure time was available as a measure of the approximate exposure intensity. The mean (SD) exposure time in the whole series was $6 \cdot 1(3 \cdot 4)$ years with a range between 2 and 10 years. In the subjects with features of connective tissue diseases it was slightly longer (mean value 6.4 years) than in those without disease (mean value 5.7 years); these differences did not reach statistical significance $(p=0.6685)$. The mean times of exposure for the various diseases were $5 \cdot 3$ years for SLE, eight for systemic sclerosis, and $6 \cdot 7$ for SLE/systemic sclerosis; these differences were not statistically significant $(p=0 \cdot 09)$. The latency time from first exposure until the appearance of symptoms was $11 \cdot 8(5 \cdot 9)$ years.

\section{CLINICAL MANIFESTATIONS}

Thirty two (64\%) subjects had features of a systemic disease; the most relevant are given in table 1. Three cases of primary Sjögren's syndrome (not associated with another collagen disease) are included in the group 'undefined

Table 1 Clinical data of the 50 subjects studied. Values are No (\%) of subjects with the clinical manifestation

\begin{tabular}{lc}
\hline Cutaneous manifestations & $32(64)$ \\
Malar erythema & $12(24)$ \\
Cutaneous sclerosis & $10(20)$ \\
Generalised sclerosis & $2(4)$ \\
Limited to extremities & $8(16)$ \\
Sclerodactyly & $2(4)$ \\
Digital ulcers & $7(14)$ \\
Digital necrosis & $1(1)$ \\
Calcinosis & $1(2)$ \\
Dryness of eyes or mouth, or both & $29(58)$ \\
Complete Sjögren's syndrome & $9(18)$ \\
Primary Sjögren's syndrome & $3(6)$ \\
Raynaud's phenomenon & $14(28)$ \\
Oesophageal abnormalities & \\
Subjective manifestations & $10(20)$ \\
Radiological abnormalities & $11(22)$ \\
Delay in isotopic transit & $21(42(72))$ \\
Oesophagomanometric abnormalitiest & $4(8(57))$ \\
Respiratory abnormalities & $19(38)$ \\
Dyspnoea & $17(34)$ \\
Chest radiographic abnormalities & $24(48)$ \\
Silicotic pattern & $18(36)$ \\
Diffuse pulmonary fibrosis & $14(28)$ \\
Pleural thickening & $3(6)$ \\
Pleural effusion & $2(4)$ \\
'Eggshell' nodes & $7(14)$ \\
Functional study abnormalities & $16(32)$ \\
Articular manifestations & $21(42)$ \\
Arthralgias & $20(40)$ \\
Morning stiffness & $11(22)$ \\
Non-erosive arthritis & $5(10)$ \\
Neurological abnormalities & $1(2)$ \\
\hline &
\end{tabular}

^Twenty nine subjects. †Seven subjects. 
collagen diseases'. The remaining six cases were secondary and associated with two cases of systemic sclerosis, one SLE, and three cases of overlap syndrome (SLE/systemic sclerosis). The presence of Raynaud's phenomenon was closely correlated with the presence of sicca syndrome $(\mathrm{p}<0 \cdot 01)$.

We specifically analysed the respiratory aspects related to silicosis; $18(36 \%)$ subjects had compatible lesions (four without features of systemic diseases; five with defined connective tissue disease-one with systemic sclerosis, one with SLE, and three with overlap syndrome; nine with 'undefined collagen diseases'). We therefore detected a silicotic pattern in four (28\%) of 18 patients without symptoms and in $14(43 \%)$ of 32 patients with immunological abnormalities; these differences are not statistically significant $(p=0 \cdot 11)$. Functional respiratory studies were performed in 29 patients; in $16(32 \%)$ subjects several abnormalities were detected, sometimes several in the same patient: five (31\%) had restrictive spirographic patterns and three $(20 \%)$ obstructive patterns.

With respect to articular symptoms, nonerosive arthritis of the hands was present in five patients: two with SLE, one with systemic sclerosis, and two with overlap syndromes.

The only neurological abnormality detected was a sensory neuropathy of the $\mathrm{V}$ cranial nerve in a patient with overlap syndrome.

In summary, consistent features of systemic disease were found in $32(64 \%)$ subjects (29 women and three men) (table 2). The higher prevalence in women is apparent, but only reflects the imbalance of men and women in the group studied $(p=0 \cdot 99)$.

\section{LABORATORY TESTS}

Table 3 gives a summary of the biological and immunological abnormalities. Anaemia corresponded to the type of chronic inflammatory disease. Fifteen subjects were repeatedly defined as having leucopenia (leucocytes $<4.5 \times 10^{9} / 1$; for the SLE criteria a value of less than $4 \times 10^{9} / 1$ was applied). No quantitative abnormalities were shown in the thrombocytes.

Antinuclear antibodies were positive in 36 $(72 \%)$ subjects. They included $28(88 \%)$ of the 32 subjects with symptoms of rheumatic or connective tissue diseases. The cumulative frequency curve showed 25 subjects with a titre equal to or greater than $1 / 80$, and 19 equal to or greater than $1 / 160$. The highest titres $(1 / 1280)$ were detected in five subjects. The most common finding was the mixed pattern, ${ }^{12}$

Table 2 Clinical diagnosis in 50 subjects exposed to silica. Values are No (\%) of subjects studied

\begin{tabular}{lr}
\hline Systemic sclerosis (SSc) & $5(10)$ \\
Systemic lupus erythematosus (SLE) & $3(6)$ \\
Overlap syndrome (SLE/SSc) & $5(10)$ \\
Secondary Sjögren's syndrome* & $6(12)$ \\
Undefined collagen diseases† & $19(38)$ \\
Asymptomatic subjects & $18(36)$ \\
\hline
\end{tabular}

*Included in the three first clinical diagnosis.

†Including three cases of primary Sjögren's syndrome.
Table 3 Biological and immunological data. Values are No (\%) or subjects affected

\begin{tabular}{lc}
\hline Anaemia (haemoglobin< $<110 \mathrm{~g} / \mathrm{l})$ & $6(12)$ \\
Leucopenia $\left(<4 \cdot 5 \times 10^{9} / \mathrm{l}\right)$ & $15(30)$ \\
Lymphopenia $\left(<1 \cdot 5 \times 10^{9} / \mathrm{l}\right)$ & $21(42)$ \\
Increased erythrocyte sedimentation rate & $19(38)$ \\
$(>30 \mathrm{~mm} / \mathrm{h})$ & $4(8)$ \\
Abnormal muscular enzymes & $12(22)$ \\
Presence of rheumatoid factor & $13(26)$ \\
Presence of C reactive protein & $13(26)$ \\
Hypergammaglobulinaemia $(>18 \mathrm{~g} / \mathrm{l})$ & $12(22)$ \\
Decreased C3 or C4, or both & $16(32(43))$ \\
Presence of cryoproteins & $36(72)$ \\
Antinuclear antibodies & $4(8)$ \\
Antibodies to native DNA & \\
HEp-2 substrate patterns $\ddagger$ & $21(42)$ \\
Homogeneous & $9(18)$ \\
Antinucleolar & $11(22)$ \\
Speckled non-anticentromere & $0(0)$ \\
Anticentromere & $14(28)$ \\
Negative &
\end{tabular}

^Thirty seven subjects.

$\dagger$ Rat liver, kidney, stomach; titre $>1 / 20$.

$\ddagger$ Some patterns were concomitant.

present in 27 serum samples. In spite of the scleroderma-like features found in these subjects, none had anticentromere antibodies. The study of antibodies against extractable nucleas antigens showed two (4\%) subjects positive for SS-B, two (4\%) for SS-A, one ( $2 \%$ ) for $\mathrm{Sm}$, one $(2 \%)$ for $\mathrm{nRNP}$, and two $(4 \%)$ for Scl-70. Some of these specificities were found in the same patient.

Tissues were typed for HLA-A and HLA-B antigens in 48 of 50 subjects; in 41 of these HLA-DR typing was also performed. Owing to the lack of a control population not exposed to silica from the same environment and the presence of several pairs of siblings in the population studied, only a comparison of the HLA antigen frequencies between affected and non-affected subjects was made. The frequency of the HLA antigens was not significatively different between the two groups. The DR3 antigen had a high prevalence in the affected subjects, whereas the prevalence in healthy subjects was close to the frequency in the general population of Spain, ${ }^{13}$ although this was not statistically significant (see table 4). A comparison of clinical diagnosis, autoantibody type, and HLA phenotype in each pair of siblings did not reveal any influence of the HLA phenotype on the occurrence of a silica related illness (see table 5).

\section{Discussion}

Caplan was the first to report an association between rheumatoid arthritis and a specific variety of pulmonary lesions in subjects exposed to silica. ${ }^{2}$ His discussion did not analyse the possible role of silica in triggering autoimmune processes as he considered the disease to be a simple anatomoclinical form of

Table 4 Results of tissue typing. Values are No (\%) of subjects studied

\begin{tabular}{llll}
\hline Patients & $D R 3+$ & $D R 3-$ & Total \\
\hline Affected & $15(58)$ & $11(42)$ & 26 \\
Not affected & $4(27)$ & $11(73)$ & 15 \\
Total & 19 & 22 & 41 \\
\hline$\chi^{2}$ test $=3 \cdot 68 ; \chi^{2}$ with & Yates's correction $=2 \cdot 54, p<0 \cdot 106 ;$ Fisher's \\
exact test $\mathrm{p}=0 \cdot 054$. &
\end{tabular}


Table 5 Serological, diagnostic, and genetic correlations in siblings exposed to silica

\begin{tabular}{|c|c|c|c|}
\hline Family/members & Diagnosis* & Antibodies† & No of shared haplotypes \\
\hline $\begin{array}{l}1-\mathrm{A} \\
1-\mathrm{B} \\
2-\mathrm{A} \\
2-\mathrm{B} \\
3-\mathrm{A} \\
3-\mathrm{B} \\
4-\mathrm{A} \\
4-\mathrm{B} \\
4-\mathrm{C} \\
5-\mathrm{A} \\
5-\mathrm{B} \\
5-\mathrm{C} \\
6-\mathrm{A} \\
6-\mathrm{B} \\
7-\mathrm{A} \\
7-\mathrm{B}\end{array}$ & $\begin{array}{l}\text { SLE/SSc/SSS } \\
\text { Sc/SSS } \\
\text { SLE/SSc/SSS } \\
\text { UD } \\
\text { SLE } \\
\text { SLE/SSS } \\
\text { SLE/SSc/SSS } \\
\text { UD } \\
\text { SSc/SSS } \\
\text { No } \\
\text { No } \\
\text { UD } \\
\text { UD/PSS } \\
\text { No } \\
\text { No } \\
\text { UD }\end{array}$ & 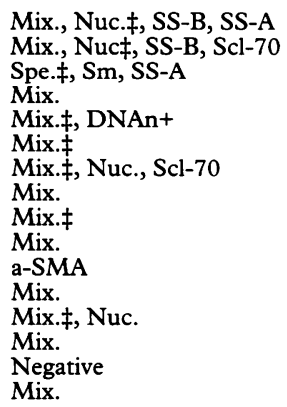 & 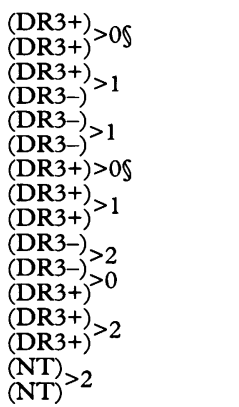 \\
\hline
\end{tabular}

^SLE=Systemic lupus erythematosus; SSc=systemic sclerosis; SSS=secondary Sjögren's syndrome; UD=undefined collagen disease; No=no clinics; PSS=primary Sjögren's syndrome. †Antinuclear antibody patterns: Mix.=mixed; Nuc.=nucleolar; Spe.=speckled; a-SMA=antismooth muscle antibodies.

tVery high titre of antibodies.

SDR3 inherited from a haplotype different to the DR3 of the sister(s), NT=Not tested.

ণMale. rapidly progressive glomerulonephritis in a patient with an acute silicoproteinosis; Hatron et $a l^{34}$ reported four cases of SLE in coal miners; and Bernardini and Iannacone ${ }^{35}$ and Cledes $e t a l^{36}$ reported silicosis associated with SLE.

This study describes a high prevalence of autoimmune abnormalities in a restricted cohort chronically exposed to silica. Autoimmune processes were present in $32(64 \%)$ of the 50 subjects studied.

Even if we assume that the remaining 250 factory workers had not been affected, the frequency of systemic diseases in this group would be $10 \cdot 6 \%$. The prevalence for SLE in the general population is $1-3 / 100000$ subjects, ${ }^{37}$ but in this series it increased to $16 \%$ (three with SLE and five with SLE/systemic sclerosis); even if we reduce this proportion to $2.6 \%$ the difference is definite. Systemic sclerosis appeared in $10(20 \%)$ patients (five with systemic sclerosis and five with systemic sclerosis/SLE), with $2(3 \%)$ as a minimum, whereas its prevalence in the general population is even lower than that of SLE; the calculated annual incidence is $4 \cdot 5-12 / 10^{6}$ subjects. ${ }^{38}$ Although some workers ${ }^{417}$ have found a male predominance in scleroderma secondary to silica exposure, our experience shows a higher frequency (around 10:1) in women. The first published series was from an environment in which only men work (coal mining), whereas our group predominantly consists of women; there was no difference $(p=0.99)$ between the ratio of men to women in the studied series $(6: 44)$ and the affected subjects (3:29). The apparent imbalance depends on the sex bias of the group studied.

The latency time from first exposure until the appearance of symptoms was long (11.8 years), but the average exposure time in the whole series ( $6 \cdot 1$ years), in the subjects with features of connective tissue diseases (6.4 years), or in those without disease ( 5.7 years) was not statistically significant. Therefore the appearance of systemic disease did not correlate with the exposure time.

The frequency of siblings in our patient population is high (five pairs and two groups of three). This raises the question of whether, in addition to the fundamental factor of massive and long term exposure to silica, genetic background could be important as a predisposing factor. The frequency of clinical disorders in the whole group reached $64 \%$ (32/50). In the subgroup of siblings it was $75 \%$ $(12 / 16)$. Even if we eliminate the related subjects, however, the frequency of disease is still high (20/34 (59\%)).

A possible implication of the HLA system in the susceptibility for developing autoimmune diseases after exposure to silica was investigated. When we compare the frequencies of HLA antigens in healthy and affected subjects, we observe a high frequency of HLA-DR3 in the second group; however, this is not statistically significant. On the other hand, comparing each pair of siblings and their respective diagnosis, antibody type and titre, and the number of HLA shared haplotypes, no antinuclear antibodies and rheuma and pneumoconiosis and Jones et $a l^{32}$ reported a high prevalence of antinuclear antibodies in subjects exposed to silica. Giles et al $^{33}$ reported 
association between HLA antigens and the type of immunopathological manifestation can be detected.

We also observed a surprising variability in the clinical response, with a wide range of features present in the various systemic diseases. There was an overall predominance of the pattern of 'undefined collagen diseases' and 'overlap syndromes'. Nevertheless, we observed a number of patients with SLE or systemic sclerosis whose features were the same as in the primary forms of these diseases. A striking feature, however, was the constant absence of anticentromere antibodies, common in systemic sclerosis (particularly in localised forms), and the presence of an antibody to $\mathrm{Sm}$ in a patient with a predominance of systemic sclerosis features.

In conclusion, we have described a group of subjects exposed to the same exogenous insult, silica, who developed systemic diseases or autoantibodies, or both, of considerable heterogeneity, which do not seem to be linked to any particular HLA phenotype.

We are indebted to Mrs Cristina Simón Moreno de Vega, Mrs Carmen Martino, and Mrs Rosario Magariño for excellent technical assitance and to Dr Robert J Winchester (New York University) for insightful discussions and encouragement. This University) for insightful discussions and encouragement. This
work was supported by grants $(88-0926 ; 89-0001$ and 89-0009) work was supported by grants (88-0926; 89-0001 and 89-0009)
from the 'Fondo de Investigaciones Sanitarias de la Seguridad Social', Ministerio de Sanidad y Consumo, Spain.

1 Bramwell B. Diffuse sclerodermia: its frequency; its occurrence in stone masons: its treatment by fibrolysis in elevations of temperature due to fibrolysis injections. Edinburgh Medical fournal 1914; 12: 387

2 Caplan A. Certain radiological appearances in the chest of coal-miners suffering from rheumatoid arthritis. Thorax 1953; 8: 29-37.

3 Erasmus L D. Scleroderma in gold-miners on the Witwatersrand and with particular reference to pulmonary manifestations. South African fournal of pulmonary manifestations. South African fourn

4 Rodnan G P, Benedek T G, Medsger Jr T A, Cammarata $\mathrm{R} J$. The association of progressive systemic sclerosis (scleroderma) with coal miners' pneumoconiosis and other forms of silicosis. Ann Intern Med 1967; 66: 323-34

5 Tan E M, Cohen A S, Fries J F, et al. The 1982 revised criteria for the classification of systemic lupus erythematosus. Arthritis Rheum 1982; 25: 1271-7.

6 Subcommittee for Scleroderma Criteria of the American Rheumatism Association (ARA). Preliminary criteria for the classification of systemic sclerosis (scleroderma). Arthritis Rheum 1980; 23: 581-90.

7 De Portugal J, Fermoso J, Cordero M, Sanchez A Sindromes atípicos de conectivopatía. Rev Clin Esp 1982; 167: 207-12.

8 LeRoy E, Maricq $\mathrm{H}$, Kahaleh B. Undifferentiated connective tissue syndromes. Arthritis Rheum 1980; 23: 341-3.

9 Alspaugh $\mathrm{K} \mathrm{W}$, Alspaugh $M$. Sjögren syndrome. In: Kelley W N, Harris E D, Ruddy S, Sledge C B, eds. Textbook of rheumatology. Philadelphia: Saunders, 1985; 956-78.

10 UICC/Cincinati Classification of the appearances of pneumoconiosis: a cooperative study by the UICC committee. Chest 1970; 58: 57-68.

11 Tolin R D, Malmud L S, Reilley J, Fisher R S. Esophageal scintigraphy to quantitate esophageal transit (quantitation of esophageal transit). Gastroenterology 1979; 76: 1402-8.
12 Tan E M. Autoantibodies to nuclear antigens (ANA): their immunobiology and medicine. Adv Immunol 1982; 33: $167-240$.

13 Nunez-Roldan A, Villechenous E, Fernandez-Andrade C Martin-Govantes J. Increased HLA-DR7 and decreased DR2 in steroid responsive nephrotic syndrome. $N$ Engl f Med 1982; 306: 366-7.

14 Rodnan G P, Lipinski E, Luksick J. Skin-thickness and collagen-content in progressive systemic sclerosis (scleroderma) and localized scleroderma. Arthritis Rheum 1979 22: $130-40$.

15 Alcocer-Varela J, Martinez-Cordero E, Alarcon-Segovia D. Spontaneous production of, and defective response to, interleukin 1 by peripheral blood mononuclear cells from patients with scleroderma. Clin Exp Immunol 1985; 59: 666-72.

16 Sandborg C, Berman M, Andrews B S, Friou G J. IL-1 production by mononuclear cells from patients with production by mononuclear cells from patients
scleroderma. Clin Exp Immunol 1985; 60: 294-302.

17 Fréneaux B. Fréneaux J, Buyse N, Le Van Quyen H. L'association silicose-sclérodermie. Nouv Presse Med 1975; 4: 2087-90.

18 Devulder B, Plouvier B, Martin J C, Lenoir L. L'association sclérodermie-silicose ou syndrome d'Erasmus. Aspect cliniques et physiopathologiques. Nouv Presse Med 1977, 6: $2877-9$.

19 Aalto M, Kulonen E, Ronnemaa T, Sundstrom C, Vilpo J. Liberation of a fibrogenic factor from human blood monocytes, ascites cells, cultured hystiocytes and transformed mouse macrophages by treatment with $\mathrm{SiO}^{2}$ Scand $\mathcal{F}$ Clin Lab Invest 1980; 40: 311-8.

20 Oppenheim J J, Gery I. Interleukin-1 is more than an interleukin. Immunol Today 1982; 3: 113-9.

21 Durum S K, Schmidt J A, Openheim J J. Interleukin-1: an immunological perspective. Ann Rev Immunol 1987; 3 263-87.

22 Murphy P A, Simon P L, Willoughby W F. Endogenous pyrogens made by rabbit peritoneal exudate cells are identical with lymphocyte activating factor made by rabbit alveolar macrophages. F Immunol 1980; 124: 2498-501.

23 Schmidt J A, Oliver C N, Lepe-Zuniga J L, Green I, Gery I. Silica stimulated monocytes release fibroblast proliferation factors identical to interleukin 1. A potential role for interleukin 1 in the pathogenesis of silicosis. $\mathcal{F}$ Clin Invest 1984; 73: 1462-72.

24 Goselin R E, Hodge H C, Smith R P, et al. Clinical toxicology, of commercial products. Acute poisoning. Baltimore: of commercial products. Acute poisor

25 Middleton E L. The present position silicosis in industry in Britain. BMF 1929; 2: 485-7.

26 Middleton E L. Industrial pulmonary disease due to the inhalation of dust. With special reference to silicosis. Lancet 1936; ii: $1-6$.

27 Ritterhoff R J. Acute silicosis. Occurring in employees of abrasive soap powder industries. Americian Review of Tuberculosis 1941; 43: 117-20.

28 Gong H, Tashkin D P. Silicosis due to intentional inhalation of abrasive scouring powder. Case report with long-term survival and vasculitis sequelae. Am 7 Med 1979;67: survival

29 Lippman M, Eckert H L, Hahon N, Morgan W K Circulating antinuclear and rheumatoid factors in coal miners. A prevalence study in Pennsylvania and West Virginia. Ann Intern Med 1973; 79: 807-1 1

30 Soutar C A, Turner-Warwick M, Parkes W R. Circulatin antinuclear antibody and rheumatoid factor in coal pneumoconiosis. BMf 1974 ; 3: $145-7$.

31 Benedek T G, Zawadzki Z A, Medsger T A. Serum immunoglobulins, rheumatoid factor and pneumoconiosis in coal miners with rheumatoid arthritis. Arthritis Rheum 1976; 19: 731-6.

32 Jones $\mathrm{R} N$, Turner Warwick $M$, Ziskind $M$, Weill $H$. High prevalence of antinuclear antibodies in sandblasters silicosis. Am Rev Respir Dis 1976; 113: 393-5.

33 Giles R D, Sturgill B C, Suratt P M, Bolton W K. Massive proteinuria and acute renal failure in a patient with acute silicoproteinosis. Am $\mathcal{F}$ Med 1978; 64: 336-42.

34 Hatron P Y, Plouvier B, Francois M, Baclett J L Decconnick P, Devulder B. Association lupu érythémateux et silicose. Rev Med Interne 1982; 3: 245-6.

35 Bernardini P, Iannacone A. Silicosi pulmonare associata lupus eritematoso sistémico. Lav Um 1982; 30: 8-15.

36 Cledes J, Hervé J P, Clavier J, Youinou P, Ollivier J P. Silicose pulmonaire et lupus érythémateux disseminé Poumon Coeur 1983; 39: 205-7.

37 Winchester R J, Núnez-Roldán A. Some genetic aspects of systemic lupus erythematosus. Arthritis Rheum 1982; 25. 833-7.

38 Rocco V K, Hurd E R. Scleroderma and scleroderma-like disorders. Semin Arthritis Rheum 1986; 16: 22-69. 